\title{
The Risk of Acute Respiratory Distress Syndrome in Patients with Subarachnoid Hemorrhage, About A Case
}

\author{
Dr. Mohamed Mattous ${ }^{1 *}$, Dr. Nabil Jbili ${ }^{1}$, Dr. Jaouad Laoutid ${ }^{2}$
}

${ }^{1}$ Service de Réanimation Médicale de l'Hôpital Militaire Moulay Ismail Meknès Marocco

${ }^{2}$ Chef de service de Réanimation Médicale de l'Hôpital Militaire Moulay Ismail Meknès Marocco

DOI: $10.36347 /$ sjmcr.2020.v08i02.040

| Received: 09.02.2020 | Accepted: 16.02.2020 | Published: 28.02.2020

*Corresponding author: Mohamed Mattous

Abstract

Aneurysmal arachnoid hemorrhage (AAH) is a rare disease common in the young female population and can cause ma ny neurological complications, namely hydrocephalus, vasospasm and rebleeding. However, it can also lead to extra $n$ eurological complications, including cardiovascular failure, renal failure, metabolic disorders (hypokalaemia, hypergly cemia, dysnatremia) and acute respiratory distress syndrome (ARDS). We report a case of a 50-year-old patient who d eveloped ARDS during her hospitalization in the resuscitation department for an AAH. The occurrence of this complic ation in these patients could be explained on one hand by an activation of the sympathetic nervous system hence the ap pointment of neurogenic pulmonary edema and on the other hand by the presence of a systemic inflammatory response syndrome ( SIRS), but future studies will be needed to elucidate these pathophysiological mechanisms. According to $r$ ecent studies, the treatment of ARDS is based on a mechanical ventilation strategy that uses low volumes with high PE $\mathrm{EP}$, while prone position is a therapeutic alternative but with the risk of increased intracranial pressure. The manageme nt of aneurysmal arachnoid haemorrhage relies on the control of as well as other factors responsible for delayed ische mia and aneurysm treatment.

Keywords: Acute respiratory distress syndrome, subarachnoid hemorrhage, catecholaminergic stress, systemic inflamatory response syndrome, protective ventilation.

Copyright @ 2020: This is an open-access article distributed under the terms of the Creative Commons Attribution license which permits unrestricted use, distribution, and reproduction in any medium for non-commercial use (NonCommercial, or CC-BY-NC) provided the original author and source are credited.

\section{INTRODUCTION}

Aneurysmal arachnoid haemorrhage $(\mathrm{AAH})$ is a rare disease common in the young female population. It can cause many neurological complications, namely $\mathrm{h}$ ydrocephalus, vasospasm and rebleeding. However, it c an also lead to extra neurological complications, includi ng cardiovascular failure, renal failure, metabolic disord ers (hypokalemia, hyperglycemia, dysnatremia) and acu te respiratory distress syndrome (ARDS) [1]. We report a case of a 50-year-old patient who developed ARDS d uring her hospitalization resuscitation service for aneury smal Arachnoid hemorrhage.

\section{Clinical Observation}

A 50 years old female patient, followed for typ e 2 diabetes for 3 years under metformin, admitted to th e emergency department for intense headaches in thund erclap, vomiting and photophobia. The clinical examina tion at admission found a patient confused (GCS 14/15) , subfebrile (temperature at $37.9^{\circ} \mathrm{C}$ ), hemodynamically stable $(\mathrm{BP}=130 / 70 \mathrm{mmHg}$, Cardiac frequency $=90$ beats / min) and respiratory (16 cycles / min, $\mathrm{SpO} 2$ at $98 \%$ in ambient air), not exhibiting a sensorimotor deficit. The brain CT-scan performed revealed the presence of meni ngeal and intraventricular haemorrhage (Figure-1), the 1 umbar puncture brought a haemorrhagic liquid, incoagu lable, microscopically characterized by the presence of 14,400 red blood cells / mm3, of 3 white elements / mm 3 and without germs to direct examination, the initial ch est x-ray was normal, the electrocardiogram showed no abnormalities, troponin was slightly elevated (7 times th e normal value) and metabolic status showed hypokale mia at $3.05 \mathrm{mmol} / 1$ and hyponatremia at $130 \mathrm{mmol} / 1$. The patient had been transferred to the intensive care un it, placed in a low-light unit, put under oxygen ( $31 / \mathrm{min}$ ), antiemetic to control vomiting, nimodipine ( 2 tablets every 6 hours by the nasogastric tube) to prevent vasosp asm, paracetamol or morphine to calm headaches. The maintenance of the hemodynamic stability was essential with the aim of a Systolic blood pressure between 160 a nd $180 \mathrm{mmHg}$. The evolution was marked by the respira tory and infectious aggravation of the patient with a pol ypnea at 24 cycles / min, an $\mathrm{SpO} 2$ at $86 \%$ under oxygen (telescope), bilateral pulmonary opacities at chest x-ray, leukocytosis at 15,680 elements / $\mathrm{mm} 3$ and a CRP at 28 
$0 \mathrm{mg} / \mathrm{l} \mathrm{PaO} 2$ / FiO2 ratio was $150 \mathrm{mmHg}$. Cardiac ultr asound had eliminated cardiogenic hydrostatic edema. The diagnosis of moderate ARDS (Figure-2) and syste mic inflammatory response syndrome (SIRS) was made . Protective ventilation was set up with low current volu mes $(6 \mathrm{ml} / \mathrm{kg})$ and high PEEPs combined with antibioti c therapy. The evolution was marked by the improveme nt of the patient after one week and its transfer to the ne urosurgery department for additional support.
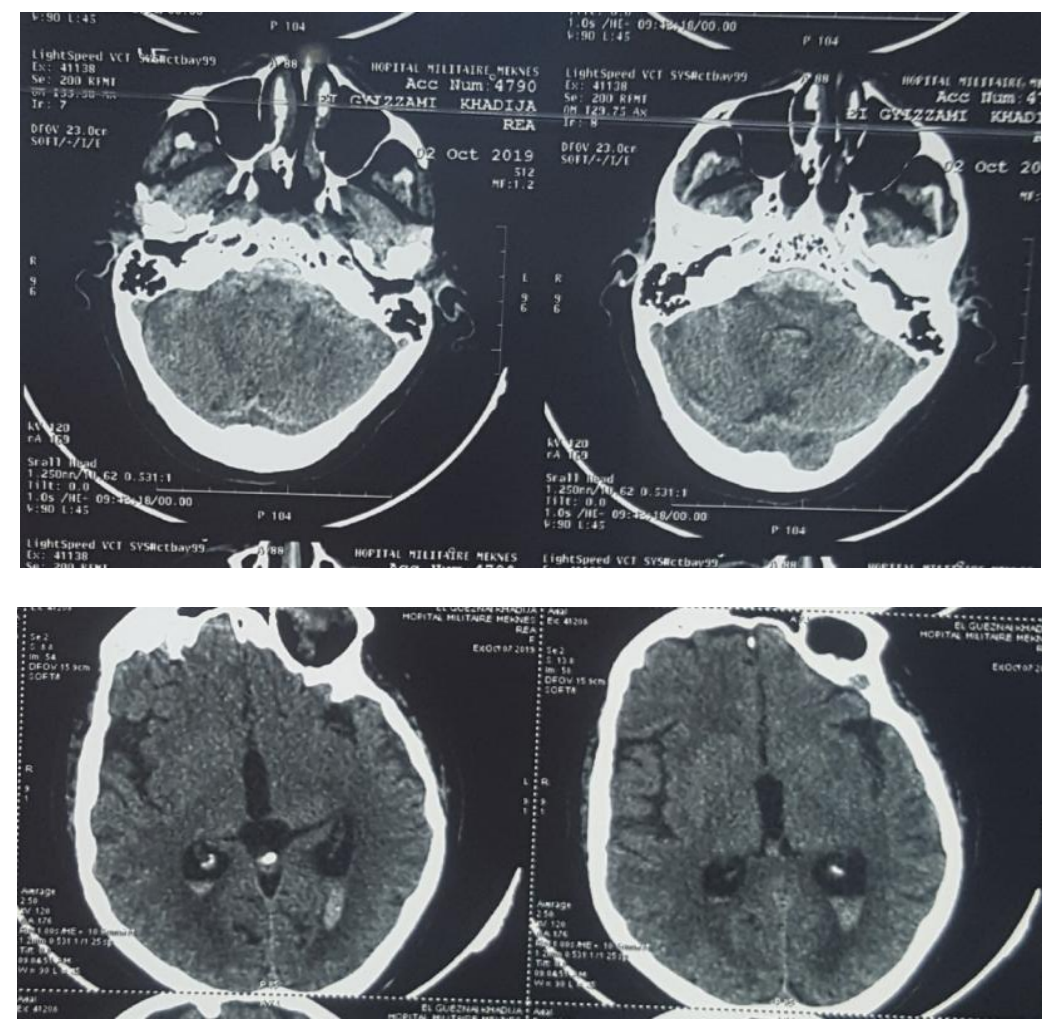

Fig-1: Brain scanner, subarachnoid and intraventricular hemorrhage

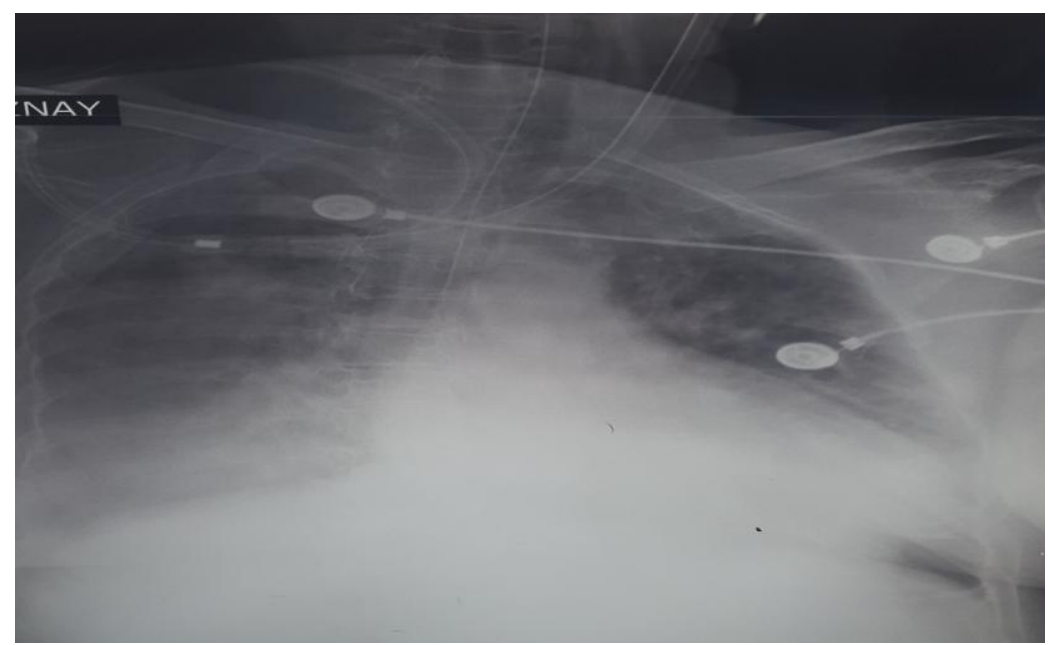

Fig-2: Pulmonary Radiography, bilateral pulmonary opacities

\section{Discussion}

According to the new Berlin definition, ARDS is defined by the installation of respiratory symptoms fo $r$ less than a week after the occurrence of a usual risk fa ctor for ARDS if it is identified, the presence of bilatera 1 pulmonary opacities radiography or chest CT scan, ex clusion of left heart failure and hypoxemia with a $\mathrm{PaO} 2$ / $\mathrm{FiO} 2$ ratio of less than or equal to $300 \mathrm{mmHg}$. There ar e 3 types of ARDS depending on the severity of this hy poxemia, mild when the $\mathrm{PaO} 2$ / FiO2 ratio is between 2 00 and $300 \mathrm{mmHg}$, moderate when it is between 100 an d $200 \mathrm{mmHg}$ and severe if it is below $100 \mathrm{mmHg}$. This is valid if the patient is under invasive, noninvasive vent ilation or VS-PEP [2]. It is responsible for significant $m$ orbidity and mortality in patients with aneurysmal arach noid hemorrhages. In fact, the mortality is of the order o f $50 \%$, and $60 \%$ of the survivors will have neurological sequelae [3]. It occurs in severe forms of The AAH (W 
FNS > 3 and / or modified Fisher score> 2) [4]. The occ urrence of this complication in these patients could be e xplained on one hand by an activation of the sympatheti c nervous system hence the appointment of neurogenic pulmonary edema and on the other hand by the presenc e of a systemic inflammatory response syndrome (5).Th e massive release of catecholamines secondary to aneur ysmal rupture would lead to myocardial lesions objectif ied by the presence of electrical abnormalities in the ele ctrocardiogram and by an increase in cardiac enzymes $i$ ncluding troponin and CPK mb [6], this catecholaminer gic discharge lasted on average seven at ten days with $n$ ormalization at the 6th month [7]. The presence of SIRS in patients with AAH increases the risk of neurogenic $p$ ulmonary edema and is of poor prognosis if present at a dmission [8]; it is manifested by a fever at admission, $h$ yper leukocytosis and elevation of CRP [9]. In the after math of aneurysmal rupture, there is a sharp increase in systemic and pulmonary vascular resistance that causes ventricular compliance impairment and then hydrostatic edema [10]. Intracranial hyperpressure outbreaks, in cas e of aneurysmal arachnoid haemorrhage, transiently cau se the increase in intravascular pressure at the origin of alveolocapillary membrane damage explaining plasma 1 eakage in pulmonary interstitial tissue [11]. Several rece nt studies suggested that a mechanical ventilation strate gy using low volumes with high PEEPs could reduce $\mathrm{m}$ ortality in these patients [12]; ventral decubitus is a ther apeutic alternative but with a risk of increased intracrani al pressure [13]. A study conducted by the National Hea rt Lung (NHL) had shown a $22 \%$ reduction in the risk o $\mathrm{f}$ death in patients ventilated at $6 \mathrm{ml} / \mathrm{kg}$ theoretical ideal weight compared to $12 \mathrm{ml} / \mathrm{kg}$ [14], the management of the AAH relies on the control of Intracranial pressure as well as other factors responsible for delayed ischemia a nd treatment of the aneurysm.

\section{Conclusion}

The pathophysiological mechanisms that may explain the association of AAH with ARDS remain to $b$ e elucidated, and future studies are needed. The strategy of mechanical ventilation based on low current volumes and high PEP would nevertheless improve the prognosi $\mathrm{s}$, reduce mortality, and reduce the duration of mechanic al ventilation.

\section{REFERENCE}

1. Heuschmann PU, Di Carlo A, Bejot Y, Rastenyte D, Ryglewicz D, Sarti C, Torrent M, Wolfe CD. European Registers of Stroke (EROS) Investigators. Incidence of stroke in Europe at the beginning of the 21st century. Stroke. 2009 May 1;40(5):1557-63.

2. Legros V. The Berlin definition of acute respiratory distress syndrome. Why is this important for medical practice? Réanimation, (2013; 22:1-2.

3. Zacharia BE, Hickman ZL, Grobelny BT, DeRosa P, Kotchetkov I, Ducruet AF, Connolly ES. Epidemiology of aneurysmal subarachnoid hemorrhage. Neurosurgery Clinics. 2010 Apr 1;21(2):221-33.

4. Solenski NJ, Haley EC, Kassell NF, Kongable G, Germanson T, Truskowski L, Torner JC. Medical complications of aneurysmal subarachnoid hemorrhage: a report of the multicenter, cooperative aneurysm study. Critical care medicine. 1995 Jun 1;23(6):1007-17.

5. Legros V, Bard M, Rouget D, Kleiber JC, Gelisse E, Lepouse C. Extra-Neurologic Complications of Subarachnoid Hemorrhage. REANIMATION. 2018 Sep 1;27(5):413-20.

6. Mayer SA, Lin J, Homma S, Solomon RA, Lennihan L, Sherman D, Fink ME, Beckford A, Klebanoff LM. Myocardial injury and left ventricular performance after subarachnoid hemorrhage. Stroke. 1999 Apr;30(4):780-6.

7. Fontes RB, Aguiar PH, Zanetti MV, Andrade F, Mandel M, Teixeira MJ. Acute neurogenic pulmonary edema: case reports and literature review. Journal of neurosurgical anesthesiology. 2003 Apr 1;15(2):144-50.

8. Yoshimoto Y, Tanaka Y, Hoya K. Acute systemic inflammatory response syndrome in subarachnoid hemorrhage. Stroke. 2001 Sep 1;32(9):1989-93.

9. Hocker SE, Tian L, Li G, Steckelberg JM, Mandrekar JN, Rabinstein AA. Indicators of central fever in the neurologic intensive care unit. JAMA neurology. 2013 Dec 1;70(12):1499-1504.

10. SARNOFF SJ, SARNOFF LC. Neurohemodynamics of pulmonary edema: II. The role of sympathetic pathways in the elevation of pulmonary and systemic vascular pressures following the intracisternal injection of fibrin. Circulation. 1952 Jul;6(1):51-62.

11. Theodore J, Robin ED. Speculations on neurogenic pulmonary edema (NPE). Am Rev Respir Dis, 1976;113:405-411.

12. Brower RG, Rubenfeld GD. Lung-protective ventilation strategies in acute lung injury. Critical care medicine. 2003 Apr 1;31(4):S312-6.

13. Ashton-Cleary DT. Prone ventilation for refractory hypoxaemia in a patient with severe chest wall disruption and traumatic brain injury. BJA: British Journal of Anaesthesia. 2011 Dec 23;107(eLetters Supplement), 1009-1010.

14. Acute Respiratory Distress Syndrome Network. Ventilation with lower tidal volumes as compared with traditional tidal volumes for acute lung injury and the acute respiratory distress syndrome. New England Journal of Medicine. 2000 May 4;342(18):1301-8. 